Original Article

\title{
COM PARISON OF THE AMOUNT OF APICAL EXTRUSION OF BACTERIA FOLLOWING THE USE OF DIFFERENT INSTRUMENTATION TECHNIQUES - AN IN VITRO STUDY
}

\author{
Mithra N. Hegde ${ }^{1} \&$ Snehal Thatte ${ }^{2}$ \\ ${ }^{1}$ Senior Professor \& Head, ${ }^{2}$ Postgraduate student, Dept. of Conservative Dentistry and Endodontics, \\ A.B. Shetty M emorial Institute of Dental Sciences, Nitte University, M angalore - 575 018, India \\ Correspondence: \\ Mithra N. Hegde, \\ E-mail : drhegdedentist@gmail.com \\ M obile : +91 98452 84411, +91 93435 61478, Fax : +91 824242495
}

\begin{abstract}
:
Objectives : The objective of this study is to compare the amount of extrusion of bacteria beyond the apical foramen after instrumentation with Crown down and Step-back techniques using a manual and engine driven nickel-titanium instruments

M aterials and Methods: Seventy-five mandibular premolars with similar dimensions were used for the study. Access cavities prepared and root canals contaminated with a suspension of Enterococcus faecalis. The contaminated teeth were then divided into three experimental groups. Group 1(Crowndown group) divided into two: Group 1-A Hand files: root canals were instrumented using K-files and Group 1B - Rotary files: root canals were instrumented using ProTaper instruments. Group II (Step-back group) divided into two: Group II A- Hand files: root canals were instrumented using K-files and group II B-Rotary files: the root canals were instrumented using Light Speed LSXinstruments. Group III (control group): no instrumentation was done.
\end{abstract}

Bacteria were extruded after preparation were collected into vials, microbiological samples were incubated in culture media for $24 \mathrm{hrs}$. The CFUs were determined for each sample. The data obtained was analyzed using the Kruskal-Wallis one way analysis of variance and Mann-WhitneyU-tests.

Results: There was a significant difference in the amount of bacteria extruded by both Crowndown and Step-back. The Step- back hand method extruded significantly more bacteria when compared with Crowndown hand technique.

Conclusion : All instrumentation techniques extruded intracanal bacteria apically. There was a significant difference in both the engine driven instrumentation techniques, while the hand instrumentation by Step-back extruded more bacteria.

Keywords: apical extrusion, bacteria, crowndown, step- back.

\section{Introduction:}

Root canal therapy is one of the main treatment options for pulpally infected teeth. The major objective of this therapy is to clean the root canal system of pulp tissue fragments, necrotic tissue, dentine chips and microorganisms. The procedure may involve the use of hand files or engine operated systems during which some amount of debris in the form of microorganisms may be extruded out into the periradicular region. This extrusion delays the healing process and is the most common cause of post instrumentation flare-ups. It can generate an acute inflammatory response, the intensity of which will depend on the number and virulence of the bacteria.

The presence of a chronic lesion acts as a trigger leading to unfavorable response to root canal therapy and an upsurge of immunological response to foreign material. ${ }^{1}$

Shaping and cleaning of the root canal system can be accomplished by mainly two types of approaches Stepback and Crowndown. Step-back method involves the preparation of the pulp space from the apical to the coronal part of the radicular canal, whereas it is reverse in case of Crowndown method. Both hand and rotary files can be used with either of the two methods.

The extrusion of infected debris has been reported in all preparation techniques even when the working length is maintained short of the apical terminus, however, the difference resides in the fact that some techniques extrude 
more debris than the others ${ }^{2}$. This fact has raised many questions regarding the extent of periapical extrusion following various instrumentation techniques. It has also made us aware of the fact that we might be actually causing greater periapical irritation.

It has been shown that techniques involving a linear filing motion usually extrude more debris than those involving some sort of rotational action thus the Step-back instrumentation produces significantly more debris than the engine driven technique and the balanced-force technique ${ }^{3}$.

During the last decade, root canal preparation with engine driven nickel-titanium instruments has become popular. Most recently advanced instrument designs have been developed to improve working safety, to shorten working time and to create a greater flare within preparations. The newer systems also provide a cleaner and smoother preparation to receive the final obturation.

Many organisms have been isolated from infected root canals like- Fusobacterium, Peptostreptococcus, Eubacterium, Propionbacterium, Veilonella, Wolinella, Prevotella, Porphyromonas. Enterococcus faecalis has long been the causative agent for persistant root canal infections and has also been identified with retreatment cases $^{4}$. These organisms are resistant to most intracanal medicaments and are of great concern if extruded beyond the apex. Any organism extruded periapically can lead to inflammatory response and delayed healing. Thus it is important to identify the techniques which force the debris in an apical direction thereby minimizing or avoiding the use of such techniques.

The purpose of this study was to compare in vitro the number of bacteria extruded apically from extracted teeth while using Step-back and Crowndown with hand and rotary driven techniques utilizing nickel titanium instruments.

\section{Materialsand methods:}

Selection and preparation of teeth: Seventy five extracted human mature mandibular premolar teeth with similar dimensions were used for the study. Digital radiographs (Intraskan DC, Skanray Technologies, Mysore, India) were taken in buccal and proximal directions to check for a single canal. All selected teeth had similar root curvatures of 0 $10^{\circ 5}$. Teeth with calcified canals and wide apical foramen were excluded from the study. The teeth were cleaned of debris and soft tissue remnants and were stored in physiologic saline at $+4^{\circ} \mathrm{C}$ until required.

Endodontic access cavities were prepared with Endo Access Bur (Dentsply Maillefer, Ballaigues, Switzerland) with a high-speed hand piece and any coronal tooth structure was replaced with acid-etched composite resin (Ceram X M ono, Dentsply, Konstanz, Germany) to create a reservoir for loading a suspension of Enterococcus feacalis (ATCC 29212). Pulp remanants were extirpated with a fine barbed broach, with care taken not to push the broach beyond the apical foramen.

Test apparatus: A model system as described by Er et al ${ }^{6}$ was used to evaluate bacterial extrusion (Fig. 1). Holes were created in the rubber stoppers of vials with a hot instrument. The tooth was inserted under pressure into the rubber stopper, which was fixed to the cementoenamel junction by means of cyanoacrylate. Two coats of nail varnish were applied to the external root surface to prevent bacterial microleakage through the lateral canals. The tooth with the rubber stopper was then fitted into the mouth of the vial. The apical part of the root was suspended within the vial, which acted as a collecting container for apically extruded material through the foramen of the root. The vials were vented with a 24-gauge needle to equalize the air pressure inside and outside the vial. The needle was used as an electrode for

A pure culture of E. faecalis (ATCC 29212) was used to contaminate the root the electronic working length determination during canal instrumentation.

Contamination with E. faecalis. canals. A suspension was prepared by adding $1 \mathrm{ml}$ of a pure culture of E. faecalis, grown in brain-heart infusion broth (Himedia laboratories Pvt Ltd, Mumbai.) for $24 \mathrm{~h}$, to fresh brain-heart infusion broth. Then McFarland standard number 0.5 was used to 
evaluate the broth to ensure that the number of bacteria was $1.5 \times 10^{8}$ colony forming units (CFU) $\mathrm{ml}^{-1}$. Before contamination of root canal, a sterile $15 \mathrm{~K}$-file was placed 1 $\mathrm{mm}$ beyond the foramen to create a hole in the nail varnish that covered the apical foramen. In this way, a standard size of foramen and apical patency was achieved. Each root canal was then filled with the suspension of $E$. faecalis using sterile pipettes, a $10 \mathrm{~K}$-file was then used to carry the bacteria down the entire length of the canals. The root canals were then dried in an incubator at $37^{\circ} \mathrm{C}$ for $24 \mathrm{~h}$.

Glass vials were filled with $0.9 \% \mathrm{NaCl}$ solution. The toothrubber stopper-needle unit was fitted into the mouth of the vial. The contaminated roots were divided into two experimental groups of 30 teeth each and one control group of 15 teeth.

Root canal preparation: One operator, using aseptic techniques, carried out the preparation and sampling procedures on each specimen under a class I laminar airflow cabinet to prevent airborne bacterial contamination. Working length in all the teeth was achieved using Propex II (Dentsply Maillefer, Ballaigues, Switzerland). The lip clip was attached to the needle, K-file was attached to the file holder cord and placed into the root canals and advanced apically until the LED read $1 \mathrm{~mm}$. Engine driven instruments were used to prepare the root canals with the help of a reduction gear handpiece at low speed (300 rpm).

A total volume of $7 \mathrm{ml} 0.9 \% \mathrm{NaCl}$ solution was used for each root canal as an irrigant because of the different number of files in groups. The irrigant was delivered by disposable plastic syringes with a 24-gauge stainless steel needle that had been passively placed down the canal, upto $3 \mathrm{~mm}$ from the apical foramen without binding.

The instrumentation sequencesused were:

GROUP I: (Crowndown): This group was further divided into two groups with 15 specimens each.

GROUP IA (Hand group): In this group the specimens were prepared with Gates Glidden(Dentsply Maillefer; Ballaigues, Switzerland) and hand K-files (Dentsply
Maillefer; Ballaigues, Switzerland) in a corono-apical direction. The coronal orifice was enlarged with decreasing sizes of Gates Glidden (No. 3 and 2) to prepare the coronal and middle third of the canal. The apical part was prepared by using hand files starting with larger files size 55 and subsequently using smaller number files deeper into the canal in sequential order till size no 30 at the working length.

GROUP IB (Rotary group): In this group the specimens were prepared with ProTaper rotary files (Dentsply Maillefer; Ballaigues, Switzerland) in a Crowndown manner according to manufacturer's instructions using a gentle in-and-out motion. Instruments were withdrawn when resistance was felt and then changed for the next instrument. The shaping file (S1) was used first and moved apically to $2 \mathrm{~mm}$ short of the working length. SX files were then used sequentially until resistance was encountered, followed by $\mathrm{S} 1$ and $\mathrm{S} 2$ to the working length for shaping the coronal two-thirds of the canal. The apical one-third was finished by using F1, F2, F3 sequentially to the working length. Once the instrument had negotiated to the end of the canal and had rotated freely, it was removed.

GROUP II: (Step-back): This group was further divided into two groups with 15 specimens each.

GROUP IIA (Hand group): In this group the specimens were prepared with hand K-files (Dentsply M aillefer; Ballaigues, Switzerland) in an apico-coronal direction. The standardized Step-back technique was used to prepare the root canal. K-files were used first with a quarter clockwise rotation followed by a pull-back motion and used repeatedly until the working length was reached. Apical preparation was continued up to size no. 30 and the Stepback was done with a reduction of $1 \mathrm{~mm}$ for each file until size 55 .

GROUP II B (Rotary group): In this group the specimens were prepared with Lightspeed LSX ( LightSpeed Technology Inc., San Antonio, Texas) in an apico-coronal direction. Firstly the initial apical rotary size was selected, then apical preparation was done till size no. 30 as master apical file. Step-back preparation was done till size no. 55 
by progressively decreasing $1 \mathrm{~mm}$ from the working length.

Group III: Control group- No instrumentation was performed for this group.

At the end of the preparation, $0.01 \mathrm{ml}$ of $\mathrm{NaCl}$ solution was taken from the experimental vials to count the bacteria; the suspension was plated on brain-heart agar at $37^{\circ} \mathrm{C}$ for $24 \mathrm{~h}$. Colonies of bacteria were counted using the classical counting technique ${ }^{7}$ and the results were given as number of Colony Forming Units.

Statistical analysis: The data was interpreted using the SPSS software version 15.0. It was analysed using Kruskal Wallis one-way analysis of variance and Mann-Whitney U-tests. The level of statistical significance was set at $p=0.05$.

\section{Results:}

The mean and standard deviation for each instrument group are presented in table 1. M ost apical bacteria were extruded when K-type files were used in step-back technique. There was no statistically significant difference between Protaper and Lightspeed group $(p>0.05)$.

\section{Discussion :}

The aim of this study was to assess the apical extrusion of intracanal bacteria as a result of root canal shaping by Crowndown and Step-back technique. During biomechanical instrumentation of the root canal, necrotic debris, remnants of pulp tissue, microorganisms or irrigation solution can enter the periapical tissue and induce an inflammatory reaction ${ }^{8}$. Presence of infected dentinal shaves in periapical area can delay the healing procedure. Various techniques were also used for the efficient cleaning and shaping like Step-back, Crowndown, Balanced force and Hybrid technique. All methods of instrumentation have shown extrusion of some amount of debris into the periradicular area $3,9,10,11,12$. Many factors affect the amount extruded, such as: instrumentation technique, instrument type, size, preparation end point and irrigation solution ${ }^{3,10,13,14}$. Although the method of use(i.e. rotational motion) is similar for these types of instruments, but due to varying cutting action there are differences in the amount of apically extruded bacteria.
The ProTaper system have characteristic features which include a progressive taper and a modified guiding tip. They demonstrate a convex, triangular cross-section design, which results in a reduced contact area between the dentin and the cutting blade. The variable helical angle and balanced pitches allow for debris removal and prevent the instrument from screwing into the dentinal walls ${ }^{15}$. The unique features Lightspeed LSX include short cutting heads; and long, noncutting, taperless shafts.The cutting heads are designed to operate in a continuous clockwise rotation and have three radial lands and three U-shaped spiral grooves between the radial lands. The spiral grooves help to transport debris coronally, whereas the radial lands and noncutting pilot tips help rotating LightSpeed instruments to remain better centered in canals ${ }^{16}$

In the present study $0.9 \%$ normal saline was used for irrigation to rule out any reduction in the bacterial count as a result of medication, such that the extrusion would be purely due to the instrumentation technique employed ${ }^{17}$. Sequeira et al demonstrated that the instrumentation by hand or rotary instruments and irrigation by saline solution removed more than $90 \%$ of the bacterial cells from the root canal ${ }^{18}$. Vinde Visse and Brilliant found that instrumentation with irrigant produced extrusion, whereas instrumentation without irrigant produced no collectible debris $^{2}$. During irrigation of the canals, there is also a risk of passing the debris to the periapical area thus irrigation should be done passively ${ }^{10}$.

To increase the probability that the amount of apically extruded bacteria were purely due to instrumentation, a standardized tooth model was used. The teeth used for the study were carefully selected based on tooth type, straight canal and canal curvature ${ }^{17}$. This ensured that the number of bacteria extruded apically were due to the instrumentation techniques and not due to variation in tooth morphology.

Enterococci faecalis was used as the bacteriological marker. This bacteria is normally found in the human intestine but is also found in the oral cavity ${ }^{19,20,21,22}$. It is a nonfastidious bacterium of significant clinical importance ${ }^{6}$. It has been 
implicated in persistent root canal infections and more recently has been identified as the species most commonly recovered from the root canals of teeth with posttreatment disease $\mathrm{e}^{23,24}$.

The results of this study demonstrated that all instrumentation techniques tested extruded some amount of bacteria apically ex vivo. The rotary instrumentation extruded small amounts of bacteria. This could be due to the rotary motion which tends to direct debris toward the orifice by packing the debris into the flutes of the instrument ${ }^{9}$, avoiding its compaction in the root cana ${ }^{10}$.

In the present study Step-back technique extruded more bacteria when hand files were used as compared to LightSpeed. Similar results were obtained in the study conducted by Reddy ${ }^{8}$ and Beeson et al ${ }^{9}$. While comparing the Crowndown hand and rotary groups, both the technique extruded bacteria apically but the difference was not significant. When preparation was performed using hand instruments with Step-back and Crowndown method, the Step-back technique extruded significantly more bacteria. Similar results were obtained by Reiz-

Table 1: The comparison of colony forming units between the groups

\begin{tabular}{|l|r|r|r|}
\hline Group & $\mathrm{N}$ & Mean & Std. Deviation \\
\hline Group I A & & & \\
Crowndown (hand) & 15 & 5.3800 & 3.71583 \\
\hline Group I B Crowndown (rotary) & 15 & 34.5267 & 41.27079 \\
\hline $\begin{array}{l}\text { Group II A } \\
\text { Step-back (hand) }\end{array}$ & 15 & 47.3667 & 40.73532 \\
\hline $\begin{array}{l}\text { Group II B } \\
\text { Step-back (rotary) }\end{array}$ & 15 & 5.0800 & 5.29423 \\
\hline Group III Control & 15 & 1.0267 & 1.15478 \\
\hline
\end{tabular}

Chi-Square 19.728

References:

1. Seltzer S, Naidrof IJ. Flare ups in endodontics: etiological factors. Journal of Endodontics 1985; 11: 472-8

2. Vande Visse JE, Brilliant JD. Effect of the irrigation on the production of extruded material at the root apex during instrumentation. Journal of Endodontics 1975; $1: 243-6$

3. Al-omari, Dummer. Canal blockage and debris extrusion with eight preparation techniques. Journal of Endodontics 1995; 21: 154 - 8

4. Engstrom B. The significance of enterococci in root canal treatment. Odontoligisk Revy 1964; 15: 87-106

5. Schneider SW. a comparison of canal preparations in straight and curved root canals. Oral Surgery, Oral Medicine, and Oral Pathology 32,271-5.

6. Er K Sumer Z, Akpinar KE. Apical extrusion of intracanal bacteria following use of two engine driven instrumentation techniques.
Hubard et $\mathrm{al}^{40}$. Push and pull of filing motion of Step-back technique tends to push more debris apically as the K-file acts as a plunger to force the debris ahead of the file, through the patent apical foramen. However when the rotary techniques were compared it was seen that there is not a significant difference in the amount of extrusion as was observed by Er et al ${ }^{14}$ and Kustarci et al ${ }^{23}$.

This study was an in vitro study; different results may be achieved in vivo as the periapical tissues may serve as a natural barrier, inhibiting bacterial and debris extrusion. Results may also differ because of positive or negative pressure at the apex and with normal or pathological tissues.

\section{Conclusion:}

The following conclusions can be drawn from this study both instrumentation techniques extruded bacteria through the apical foramen. Step-back hand instrumentation technique extruded more bacteria as compared to the other groups. The ProTaper and Lightspeed rotary files extruded bacteria in the periapical region but the difference was not significant.

Fig 1 : Experimental model used for the study

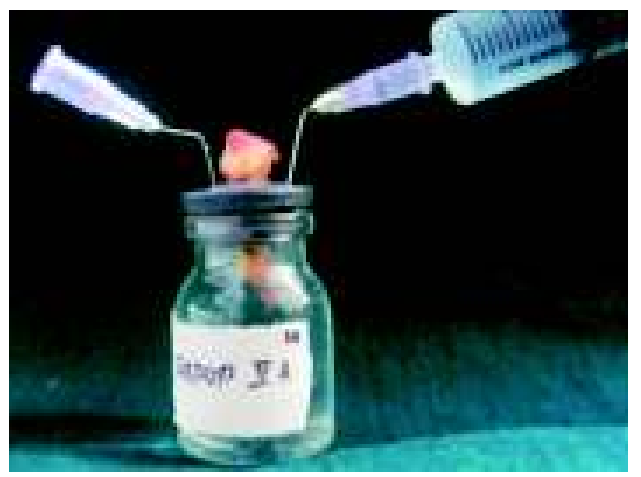

International Endodontic Journal 2005; 38: 871- 6 .

7. Collins CH, Lyne PM , Grange JM 1995 Counting methods. In: Collins $\mathrm{CH}$, Lyne PM , Grange JM , eds. Collins' and Lyne's M icrobiological M ethods. $7^{\text {th }}$ edn. Oxford, London: Butterworth Heinemann, pp. 149-62.

8. M aryam Bidar, DDS; Akbar Fallh Rastegar, DDS; Pari Ghaziani, DDS; and M. Sadegh Namazikhah, DM D, M SEd, Evaluation of Apically Extruded Debris in Conventional and Rotary Instrumentation Techniques, September 2004 Vol.32.No.9.CDA.Journal

9. Reddy SA, Hicks ML. Appical extrusion of debris using two hand and two rotary instrumentation techniques. Journal of Endodontics 1998; $24: 180-3$

10. Beeson T. Hartwell G, Thornton J, Gunsolley J. Comparision of debris extruded apically in straight canals: convention filing versus profile .04 taper series 29. Journal of Endodontics 1998:24: 255-61

11. Ferraz CCR, Gomes NV, Gomes BPFA, Zaia AA, Teixeria FB. Suoza- Filho 
F]. Apical extrusion of debris and irrigants using two hand and three engine driven instrumentation techniques. International Endodontic Journal 2001; 34: 354-8

12. Tinaz AC, Alacam T, Uzun 0 , Maden M, KayaogluG. The effect of disruption of apical constriction on periapical extrusion. Journal of Endodontics 2005; 31: 533-5

13.Fairbourn DR, Mc Walter GM, Montgomery S. The effect of four preparation techniques on the amount of apically extruded debris. Journal of Endodontics 1987; $13: 102-8$

14. Vande Visse JE, Brilliant JD (1975J) Effect of the irrigation on the production of extruded material at the root apex during instrumentation. Journal of Endodontics 1, 243-6.

15. Ajay Logani, Naseom Shah. Apically extruded debris with three contemporary $\mathrm{Ni}$-Ti instrumentation systems: An ex vivo comparative study. Indian J Dent Res 19(3) 2008.

16. Ruiz-M ubard EE, Gutmann JL, Wagner MJ. A quantitative assessment of canal debris forced penapically during root canal instrumentation using two different techniques. J Endodon 1987;12:554-8.

17. A. Kustarci, K. E. Akpinar, Z. Sumer, K.Er and B. Bek. Apical extrusion of intracanal bacteria following the use of various instrumentation techniques. International Endodontic Journal 2008; 41: 1066- 1071.

18. Siqueira JF, Lima KC, Magalhaes FA, Lopes HP, de Uzeda M 1999
Mechanical reduction of bacterial population in the root canal by three instrumentation techniques. Journal of Endodontics 25, 332-5.

19. Haapasalo M, Ranta H. Ranta KT (1983) Facultative gram negative enteric rods in persistent periapical infections. Acta Odontolgica Scandlnavica 41, 19-22.

20. McCrary BR, Streckfuss JL, Kene HJ (1989) Oral hygiene and the prevalence of oral group D streptococci in medically-physically compromised and periodontal disease patients. Journal of Periodontology 60, 255-8.

21. Rams TE, Feik D. Listgarten MA, Slots J (1992) Enterococci in human periodontitis. Oral M icrobiology and Immunology 7. 249-52.

22. Smith CJ, Halpenny M K, Ballagh SJ (1987) Carriage rates of enterococci in the dentinal plaque of haemodialysis patients in Dublin. British Journal of Oral and M axillofacial Surgery 25. 21-33.

23. Sundqvist G, Fidgor D, Persson S. Sjogren U (1998) Microbiologic analysis of teeth with failed endodontic treatment and the outcome of conservative retreatment. Oral Surgery, Oral Medicine, and Oral Pathology 85. 86-93.

24. Siqueira JF, Rocas IN (2004) Polymerase chain reaction-based analysis of microorganisms associated with failed endodontic treatment. Oral Surgery. Oral Medicine, Oral Patholol-ogy. Oral Radiology and Endodontics 97, 85-94. 